\title{
CONTRIBUIÇÕES DO DESIGN DE AMBIENTES PARA A VALORIZAÇÃO DO TERRITÓRIO: proposta para uma casa de cultura baseada na personagem Hilda Furacão
}

\author{
Paula Glória Barbosa \\ Escola de Design - Universidade do Estado de Minas Gerais \\ paulaglbarbosa@gmail.com \\ Priscila Bruna Medeiros Ferreira \\ Escola de Design - Universidade do Estado de Minas Gerais \\ priscilabmferreira@gmail.com \\ Lia Krucken Pereira \\ Escola de Design - Universidade do Estado de Minas Gerais \\ lia.krucken@gmail.com
}

Resumo: O artigo apresenta uma discussão sobre a atuação do designer de ambientes visando à valorização do patrimônio cultural de uma região. Apresenta, também, um caminho para viabilizar essa atuação, exemplificado por meio da ideação de um espaço cultural em Belo Horizonte. O projeto da casa de cultura para a capital mineira, desenvolvido em 2013 como trabalho de graduação, tem o objetivo de preservar a memória da cidade a partir de um recorte histórico - décadas de 1950 e 1960 -, divulgar seus artistas contemporâneos e proporcionar ao público uma imersão nesse patrimônio por meio de ambiências que propiciem a exploração das interações entre indivíduo, arte, identidade e história, tomando, como ponto de partida, a personagem Hilda Furacão. Este trabalho se baseia em pesquisa bibliográfica e se justifica pelas evidentes demandas contemporâneas de ressignificação dos espaços destinados ao estudo, à discussão, à conservação e à exposição de objetos de arte e de história de uma sociedade. As reflexões apontam para a relevância da contribuição do design de ambientes na conformação de espaços culturais.

Palavras-chave: design de ambientes, valorização do território, patrimônio cultural, casa de cultura.

Abstract: The article presents a discussion about the interior designer's performance aiming to value a region's cultural heritage. It also presents a way to make feasible this performance, exemplified by the ideation of a cultural place in Belo Horizonte. The culture house's project for the Minas Gerais' Capital, developed in 2013 as the final paper, has the objective of 
preserving the city's memory from a historical period - the 1950's and the 1960 's -, spreading the city's contemporary artists and affording the public an immersion in this heritage by means of an environment that provides the interactions between individual, art, identity and history. This assignment is based on bibliographic research and is justified by obvious contemporary demands for resignification of places used for studying, discussion, conservation and exhibition of a society's art and history objects. The reflections point out the relevance of interior design's contribution to cultural places.

Keywords: interior design, territory's value, cultural heritage, culture house.

\section{INTRODUÇÃO}

Os espaços culturais de um território têm importante papel enquanto meio de preservação e disseminação do patrimônio que carregam. Têm, essencialmente, o objetivo de aproximar o cotidiano dos indivíduos aos valores, aos saberes, aos costumes e à história se seu território, contribuindo para a salvaguarda e a valorização desse legado.

Para que esses espaços culturais cumpram o papel de preservar, contar e reviver esse patrimônio, devem se articular constantemente para dialogar com os usuários de maneira assertiva, conquistar novos frequentadores e se adequar às demandas culturais contemporâneas.

A cidade de Belo Horizonte, por exemplo, oferece aos seus moradores e visitantes atividades culturais em teatros, museus, parques, centros culturais e bibliotecas públicas que ainda se estruturam, majoritariamente, em modelos tradicionais, caracterizados por atividades anexas e essencialmente contemplativas.

Ao mesmo tempo, a capital mineira possui uma infinidade de atividades culturais que nem sempre são inseridas em seus "espaços tradicionais". Muitos artistas belo-horizontinos buscam meios alternativos de se expressar, ocupar a cidade e interagir com ela e seus moradores, culminando em uma grande circulação de bens culturais e na criação de novos territórios para a arte na ocupação da cidade, o que, consequentemente, deixa ao esquecimento os espaços que não possuem abertura a essa efervescência contemporânea. Contudo, percebe-se uma movimentação significativa em relação à mudança de proposta e de configuração de espaços culturais ditos tradicionais, em uma tentativa de adapta-los para dialogar com a atual sociedade.

Neste artigo, propõe-se abordar esse tema sob a perspectiva do design, área do conhecimento de natureza criativa e transversal, que se ocupa do planejamento à projetação de aspectos estético, funcional e simbólico da cultura material e imaterial da vida em sociedade, tais como os ambientes (lugares), os objetos (produtos), as comunicações (informações), os serviços e seus sistemas, a partir do desenvolvimento de projetos centrados nos usuários, sendo, sobretudo, capaz de influenciar o ambiente humano e os padrões de vida em sociedade. A prática do design, portanto, reflete os hábitos e as características de uma sociedade, podendo, também, contribuir na concretização de novos estilos de vida. 
Diante desse cenário, propõe-se discutir as contribuições do design de ambientes para a preservação e a valorização da história e da identidade de um território. Propõe-se, também, um caminho para viabilizar essas contribuições, exemplificado por meio da ideação de uma casa de cultura baseada na personagem Hilda Furacão, como forma de materialização de um conteúdo histórico da cidade de Belo Horizonte.

Desenvolvido como trabalho de graduação do curso de Design de Ambientes da Escola de Design (ED) da Universidade do Estado de Minas Gerais (UEMG), essa casa de cultura seria capaz de valorizar a atual produção cultural da cidade e preservar o conhecimento, o costume, a história e a identidade do seu território contextualizados com a mencionada personagem.

Nos próximos tópicos apresenta-se, primeiramente, o referencial teórico que fundamenta as discussões em torno das contribuições do design de ambientes para a valorização de um território. Com o objetivo de explicitar o processo de ideação e a metodologia de projeto de design nesse contexto, apresenta-se uma proposta para a Casa de Cultura Hilda Furacão. Por fim, são apontadas as principais contribuições do designer de ambientes para essa temática.

\section{REFERENCIAL TEÓRICO}

\subsection{Design de ambientes e valorização do território}

A expressão "valorização do território" tem origem na palavra francesa terroir, cujo significado remete à apropriação de um território pelo homem e a sua interferência no mesmo em âmbitos culturais, emocionais, sociais, econômicos, entre outros. (KRUCKEN, 2009).

A valorização do território em países da Europa, por exemplo, já é praticada há muitos anos em virtude do grande número de guerras e conflitos que, por consequência, geraram a demanda por proteção às tradições e às origens. Em países como o Brasil, onde se tem arraigado como referência que o "bom" é sempre proveniente do exterior - o que provoca a desvalorização da cultura local e o sentimento de desprendimento -, essa prática ainda não é muito difundida (ONO, 2004).

A globalização, por um lado, contribuiu para a configuração desse cenário. 0 desenvolvimento das mídias e dos meios de comunicação permitiu que o mundo inteiro estivesse conectado, tornando acessível aos seus quatro cantos culturas e atividades de diversas outras localidades, dando-se, muitas vezes, mais valor àquilo que vem de fora e desvalorizando-se o que é regional. Na contra mão desse processo, a globalização também incitou o sentimento de busca por aquilo que fosse autêntico, regional, que tivesse relação com a história e a origem do indivíduo e, assim, esse indivíduo sentiu a necessidade de resgatar as suas raízes, de forma a voltar os olhares para a valorização e a preservação de seu patrimônio.

O patrimônio, desse modo, está relacionado ao sentimento de perda de bens que carregam algum valor simbólico para a coletividade e que representam uma época, um grupo ou uma cultura. Práticas, lugares, edifícios, gastronomia, personagens, entre outros, são passíveis de "patrimonialização". O conjunto desses elementos de um determinado território está relacionado ao patrimônio cultural, definido pela United Nations Educational, Scientific and Cultural Organization 
(UNESCO) e adotado pelo Instituto de Patrimônio Histórico e Artístico Nacional (IPHAN), como:

[...] as práticas, representações, conhecimentos e técnicas - junto com os instrumentos, objetos, artefatos e lugares que lhes são associados - que as comunidades, os grupos e, em alguns casos, os indivíduos reconhecem como parte integrante de seu patrimônio cultural. Este patrimônio, que se transmite de geração em geração, é constantemente recriado pelas comunidades e grupos em função de seu ambiente, de sua interação com a natureza e de sua história, gerando um sentimento de identidade e continuidade, contribuindo, assim, para promover o respeito à diversidade cultural e à criatividade humana. (UNESCO, 2003).

Nesse contexto, o design é posto como área do conhecimento capaz de articular a dinamização dos recursos do território e a valorização do patrimônio cultural de modo a permitir que os valores e as qualidades locais sejam reconhecidos (KRUCKEN, 2009). Em outras palavras, o designer atua como um facilitador e um beneficiador dos produtos e serviços, no âmbito tangível e imaterial, promovendo reconhecimento e preservação de identidades e culturas regionais por meio de produtos locais, que são manifestações culturais fortemente relacionadas ao território e à comunidade que os produziu.

Somado a isso, o design contribui para a valorização de um território ao evidenciar a importância de fatores como a capacidade criativa, a qualidade do lugar e o direcionamento das atividades desenvolvidas na região. Sob essa perspectiva, um dos resultados mais significantes de um projeto de valorização territorial é o estímulo dado à capacidade criativa e empreendedora da comunidade, que possibilita a criação de produtos e serviços através da potencialização de recursos locais. Por meio de suas ferramentas e metodologias de projeto, o designer atua na identificação dessas raízes e no objetivo de transformá-las em algo que as relacione com o mundo contemporâneo. (KRUCKEN, 2009).

Ao inserir o ambiente na discussão sobre valorização do território - até então voltada para produtos -, é oportuno introduzir o conceito de "sistema produto", definido por Mauri (1996) como "[...] um sistema caracterizado por intensas e constantes inter-relações com o contexto ambiental - entendido como o mundo da natureza e o mundo das interconexões globais de caráter político, econômico, social e cultural".

Considerando a perspectiva estratégica do design, deve-se pensar não somente no produto ou serviço em si, mas em todo o sistema que compõe uma atividade onde eles são atuantes. O café, por exemplo, é um produto cuja valorização não está apenas nele, mas sim no ato de tomá-lo e em toda a atmosfera que compõe esse cenário: a recepção, o acompanhamento, a conversa, o lugar, o som, o cheiro, a forma de se tomar o café, os recipientes, entre outros.

O design pode contribuir no planejamento da experiência e na promoção do ritual relacionado à valorização da origem. Pode-se entender, então, que essa atmosfera constitua um ambiente, um conjunto de subprodutos que formam um produto maior que o espaço em si, que remonta e/ou contextualiza um cenário onde possa acontecer essa valorização da identidade local.

O ambiente, assim, deve ser pensado como um espaço que é preparado para receber os demais produtos que, em conjunto, promovem a valorização do território. É de suma importância que se estimule o reconhecimento das qualidades e dos valores (elementos sociais e culturais) relacionados aos produtos e aos ambientes locais, como 
uma forma de contribuir para tornar visível a história por trás do produto/ambiente para a sociedade, possibilitando ao usuário avaliar e apreciar uma imagem favorável do território em que o produto/ambiente se origina.

\subsection{Design, cultura e identidade}

A cultura, como destaca Ono (2004, p.54), é uma "[...] teia de significados tecida pelas pessoas na sociedade, onde desenvolvem seus pensamentos, valores e ações, e a partir da qual interpretam o significado de sua própria existência." Para Niemeyer (2010, p.78), identidade cultural é um conjunto de características comuns com o qual grupos da sociedade se identificam. A identidade cultural "[...] estabelece hábitos, 'naturaliza' comportamentos, imprime caráter a um conjunto de indivíduos".

Como dito anteriormente, a globalização trouxe como consequência o fortalecimento de identidades particulares que foram resistentes à padronização e à homogeneização, mas trouxe também a manifestação de "culturas híbridas", que são a mescla de elementos simbólicos de culturas distintas. Os produtos, nesse cenário, devem estar integrados a esse mercado mundial, mas também deveriam respeitar e atender às necessidades das identidades das culturas locais. Para Ono (2004, p.60), "[...] os objetos são elementos fundamentais no contexto e ambiente em que vivem as pessoas, e fazem parte do conjunto de referências básicas no contato do indivíduo com o mundo". O principal objetivo desse objeto é atender às necessidades do usuário, sejam funcionais (aspectos objetivos) ou simbólicas (aspectos subjetivos), em que, nessa última, assumem funções e significados particulares para cada usuário e/ou grupo social. Esses objetos são, ao mesmo tempo, um produto em si e um reflexo de uma história cultural, política, econômica e social que ajuda a moldar e a entender a sociedade.

Para Carvalho (2007), o valor de um produto está numa dimensão imaterial e este objeto ganha a partir dos significados sociais atribuídos a ele. $O$ designer, assim, posiciona-se como um agente que, por meio da análise, planejamento, escolha, recebimento e processamento de estímulos, torna-se colaborador na criação da relação entre sujeito e matéria, onde lhe é permitido escolher sobre o que pode ou não pode ser feito, e como ser feito, seja para fins industriais ou não. É, sobretudo, responsável pela decodificação do comportamento humano e pela projetação de significado de ambientes, objetos, comunicações e serviços.

\section{PROCEDIMENTOS E MÉTODOS}

O desenvolvimento deste estudo é baseado em pesquisa bibliográfica que relaciona a área do design de ambientes à preservação e valorização da cultura, história e identidade de um território. Como meio de exemplificar essa relação, desenvolveu-se, como trabalho de conclusão de curso durante o ano 2013, o projeto de design de ambientes para uma casa de cultura em Belo Horizonte. A metodologia de design utilizada considera pesquisa e criação, articulados a uma personagem que possibilita explorar aspectos culturais e históricos da mencionada cidade.

\section{UMA PROPOSTA PARA CASA DE CULTURA BASEADA NA PERSONAGEM HILDA FURACÃO}

A valorização de um patrimônio cultural está relacionada ao passado, às tradições, e abrange, dentre outros, personagens, arquiteturas e períodos históricos 
de uma cidade, como Belo Horizonte. Em muitos casos essa transposição do passado ao presente é feita por meio de museus, exposições e galerias de arte, tendo um caráter mais contemplativo e estando muitas vezes fora de contexto com a atual situação da cidade e de seus moradores.

Nesse caso, é importante lembrar que a valorização do patrimônio também está relacionada ao presente, e trata, entre outros, de movimentos culturais atuais na cidade: as artes plásticas, os coletivos, as intervenções urbanas, o teatro, a dança, a música, entre outros. É algo que está em constante evolução e movimento, acompanha as tendências sociais, além de possuir uma relação mais contemporânea com a cidade, principalmente com a ocupação de espaços urbanos antes não voltados para a expressão cultural.

Com relação ao ambiente cultural, seja ele centro, espaço ou casa de cultura, a valorização do território pode acontecer de duas formas: como ambiente tangível e como ambiente imaterial, tratando dos aspectos objetivos e subjetivos anteriormente mencionados. O ambiente tangível refere-se ao espaço físico em si e todas as características e elementos que esse espaço pode conter e contar de história para a sociedade, como a arquitetura, o mobiliário, os artefatos, o paisagismo. O ambiente imaterial, por sua vez, está relacionado, por exemplo, ao folclore, aos mitos e às personagens de uma região, às histórias que envolvem o local, que são referências e/ou fantasias daquele povo, que pertencem ao "sistema produto" e toda a sua atmosfera, mas raramente são representadas num ambiente ou produto de forma clara e interativa para os usuários.

Projetar um ambiente que permita perceber esse "patrimônio cultural imaterial" pode contribuir para a proteção das tradições da região, promovendo o fortalecimento da identidade e do sentido de pertença. Essa dimensão pode ser abordada no espaço de uma casa de cultura de diversas maneiras, e pode ser transformada em algo tangível por meio das movimentações culturais, que permitem que o ambiente deixe de ter só um caráter contemplativo e torne-se objeto de um trabalho contemporâneo, que explora sentidos e significados, causando novas interpretações naqueles que irão deslumbrar o recorte histórico.

Após o entendimento sobre as potencialidades de contribuições do design de ambientes para a valorização de um território, propõe-se a exemplificação de um modelo de espaço cultural que viabilizaria essas contribuições: o projeto de design de ambientes para a Casa de Cultura Hilda Furacão. Tem-se, como propósito, conciliar atividades museológicas e de centros culturais num modelo que proporcione, ao usuário, uma viagem no tempo.

A metodologia de projeto de design de ambientes utilizada para idealizar essa casa de cultura em Belo Horizonte contempla, basicamente, duas etapas: pesquisa e criação. Na etapa de pesquisa, o designer, acompanhado preferencialmente por uma equipe multidisciplinar, escolhe uma personagem de representatividade histórica e cultural para a sociedade em questão. Em sequência, por meio da condução de pesquisa sobre a personagem escolhida, poderá selecionar conteúdo histórico relacionado, de acordo com a intenção de projeto. A etapa de criação inclui investigar estratégias de materialização do conteúdo cultural e histórico que essa personagem carrega e - por meio de uma linguagem de projeto de design para ambientes consolidar ideias. 
O próximo tópico apresenta, detalhadamente, o projeto desenvolvido durante o ano de 2013 como trabalho de graduação do curso de Design de Ambientes da ED/UEMG, exemplificando o potencial de contribuição do designer de ambientes para a configuração de um espaço cultural.

\subsection{O projeto de Design de Ambientes para a Casa de Cultura Hilda Furacão 4.1.1 Escolha da personagem}

É possível apontar diversos patrimônios culturais, com aspectos tangíveis e imateriais, que poderiam ser valorizados em Belo Horizonte. São patrimônios relacionados aos mitos, folclores, períodos históricos relevantes, personagens, arquitetura, regiões. Um exemplo de patrimônio cultural que pode ser explorado na capital mineira é o romance Hilda Furacão, por abordar diversos pontos que podem ser trabalhados e fortalecidos por meio da valorização em um ambiente.

\subsubsection{Análise da personagem}

O livro Hilda Furacão narra a história de uma jovem da alta sociedade belohorizontina, conhecida como a Garota do Maiô Dourado, que abandona a vida de beira de piscina do Minas Tênis Clube e de missas dançantes para se refugiar na zona boêmia da cidade. Em meio à trama da personagem principal, não só a história belohorizontina é contada, mas também a brasileira, abordando aspectos sociais, políticos, econômicos, religiosos e culturais dos anos 1950 e início dos 1960, passagem essa que marca a mudança da ideia de democracia para o autoritarismo da ditadura militar (CALEGARI, 2009).

Esse período histórico corresponde ao intenso processo de modernização vivido no Brasil, determinando o fim da antiga sociedade agrária e o surgimento de uma nova sociedade, de características urbano-industriais. Essa urbanização, decorrente da industrialização, gerou uma séria de fatores sociais e políticos, como a ascensão social e econômica da população, onde muitos triunfavam no comércio, indústria e serviços, e outros fracassavam e contribuíam para constituir os núcleos marginalizados da sociedade. A narrativa aponta e desenvolve esses inúmeros personagens, ajudando a moldar a situação histórica da cidade. São prostitutas, beatas, comunistas, governantes, policiais, jornalistas, generais, políticos, malandros, exilados, boêmios e milionários, que se entrecruzam durante a trama e mostram as discrepâncias entre o velho e o novo, o arcaico e o moderno, o conservador e o revolucionário da capital mineira. (CALEGARI, 2009).

A personagem principal, por sua vez, representa todos esses opostos ditos anteriormente. Calegari (2009) acredita que Hilda seja a personagem que simboliza a mudança, a revolução, a liberdade de expressão e de comportamento. Ela é quem faz a conexão de todos os aspectos da trama. Aspectos não só ligados a outros personagens, mas a situação histórica de Belo Horizonte, onde Hilda é peça relevante em acontecimentos que surgem ao longo do romance que misturam a ficção e a realidade, deixando no ar a dúvida se ela realmente existiu. Ela está presente na construção da igreja moderna, no voto livre, nos bailes, na zona boêmia, na bossa nova e no carnaval belo-horizontino.

Essa mistura do romance com os fatos reais sempre deixaram a personagem no imaginário dos mineiros, sendo motivo de conversas e teorias em "mesas de bar", além de discussões acadêmicas sobre a obra de Roberto Drummond, que nunca 
revelou em vida o que realmente era verdade e o que era ficção em seu romance, deixando essa conclusão para os leitores.

A obra Hilda Furacão é rica e sugestiva não apenas no que diz respeito à personagem principal e aos acontecimentos de um período importante da história de Belo Horizonte. Os recursos linguísticos utilizados pelo autor/narrador contribuem para a compreensão do texto e permitem uma maior conexão do leitor com o romance, principalmente pelo estilo de escrita bastante acessível e pela história narrada em primeira pessoa, o que mostra a constante tentativa de se estabelecer diálogo entre narrador e leitor (CALEGARI, 2009). Esses recursos auxiliam numa reflexão coletiva com o narrador e exigem uma postura mais ativa de quem lê o romance. Postura essa que combina muito bem com um dos objetivos propostos no modelo apresentado neste artigo para casas de cultura.

Outro ponto que certamente pode ser valorizado é o escritor Roberto Drummond. Ele representa a literatura mineira e belo-horizontina, junto a outros grandes nomes da literatura local. Drummond foi capaz de unir fatos e pessoas reais a uma fértil imaginação, e incentiva os leitores a buscarem outras referências literárias e históricas por meio da intertextualidade que utiliza em Hilda Furacão, despertando a curiosidade para outras áreas da literatura e cultura nacional e internacional. Além disso, ele soube articular a ficção e a realidade com elementos estéticos inovadores para a época e para a literatura no Brasil.

\subsubsection{Estratégias de materialização do patrimônio cultural}

O primeiro passo do processo de materialização do conteúdo histórico e cultural que se pretendia valorizar deu-se pela escolha da edificação. Procurou-se, desse modo, uma edificação disponível que não só abarcasse todas as demandas de um projeto desse porte, mas que também mantivesse a linguagem da época e da personagem escolhida.

Após fase de busca, encontrou-se, na região leste de Belo Horizonte, o "Castelinho do Floresta", edifício de 1918 no estilo eclético (Fig. 1). Trata-se de um raro exemplar da arquitetura dos primeiros tempos da capital mineira. Constituída de três pavimentos, a edificação estava à venda no período de análise (primeiro semestre de 2013), portanto disponível para viabilização do projeto. Além disso, era perceptível o descaso com a arquitetura, mesmo após o tombamento no âmbito do Conjunto Urbano do Bairro Floresta pelo município de Belo Horizonte. Viu-se, então, a oportunidade de reconstituir um pedaço da história da cidade através da edificação e, também, associa-lo à imagem da personagem Hilda Furacão.
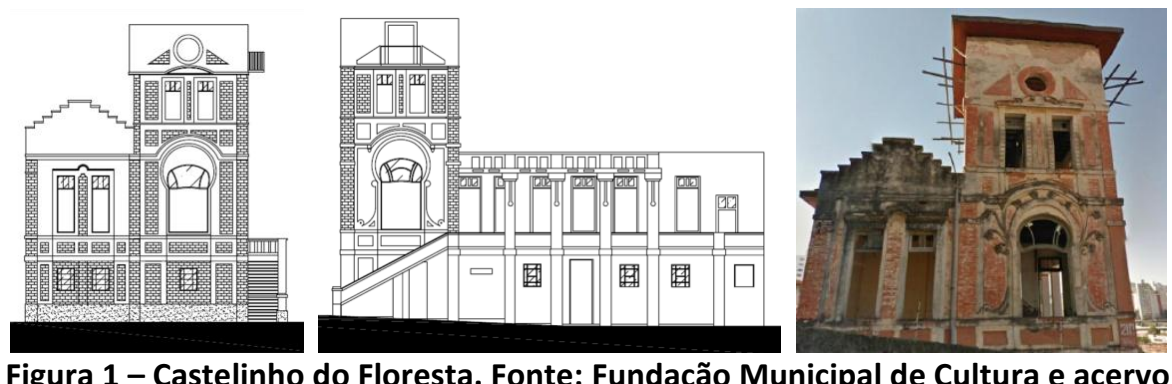

Figura 1 - Castelinho do Floresta. Fonte: Fundação Municipal de Cultura e acervo pessoal.

$\mathrm{Na}$ "Casa de Cultura Hilda Furacão" a movimentação cultural atuaria como um beneficiador da valorização do patrimônio relacionado à atmosfera Hilda Furacão, 
sendo essa movimentação inserida como parte relevante e interativa nas dependências e atividades da casa.

Dessa forma, pensou-se em um café-bar cujos cardápios valorizassem a culinária regional e a música ambiente remetesse à tocada no período histórico retratado. Haveria, também, encenações e espaços interativos que recontassem a história não só do romance do livro de Drummond, mas do contexto político, econômico e social que a cidade se encontrava nas décadas de 1950 e 1960, como a ditadura, que ganhou destaque e acervo permanente na galeria arte projetada. Além disso, ao invés de uma fotografia ou pintura, projetou-se um quarto que seria a releitura do quarto 304 - o de Hilda Furacão - no Maravilhoso Hotel.

A casa de cultura funcionaria também como um grande arquivo, recebendo e disponibilizando documentos antigos que tratam da cidade e de sua história, criando uma biblioteca que resgataria e incentivaria o desenvolvimento da cultura local, seja literatura, peça teatral, arte gráfica, música ou vídeo. Além do arquivo em si, recriou-se pequenos cinemas, os chamados cineclubes, permitindo sessões de filmes ou até mesmo palestras e conferências.

\subsubsection{Visualização das ideias por meio da linguagem de projeto de design}

O desenvolvimento do projeto de design de ambientes para a Casa de Cultura Hilda Furacão se fundamentou em pesquisa bibliográfica e no romance de Roberto Drummond (2008) para auxiliar na reconstituição da ambiência da época. Além disso, arquitetura, estilos e personagens importantes da cultura belo-horizontina foram utilizados como inspiração e diretrizes projetuais para os ambientes da casa, setorizados em recepção, cinema, arquivo de áudio e vídeo, instalações sanitárias e galeria de arte no primeiro pavimento; café-bar com leitura, instalações sanitárias, cozinha, administração e camarins no segundo pavimento; briefing room no terceiro pavimento; área externa para promoção de cinema ao ar livre, apresentação de espetáculos, extensão do café, área de descanso e contemplação, piquenique, além de carga e descarga das atividades da casa de cultura.

A recepção tem como inspiração o autor do romance, Roberto Drummond. A proposta é trazer para o ambiente o caráter comunicativo, de modo que as informações sobre o funcionamento e as atividades da casa se encontrassem nesse espaço. Os estudos de croqui (Fig. 2) avaliam a paginação do piso e a volumetria do espaço, usando de inspiração o modernismo, estilo que se desenvolveu na década de 1950 e 1960 em Belo Horizonte.
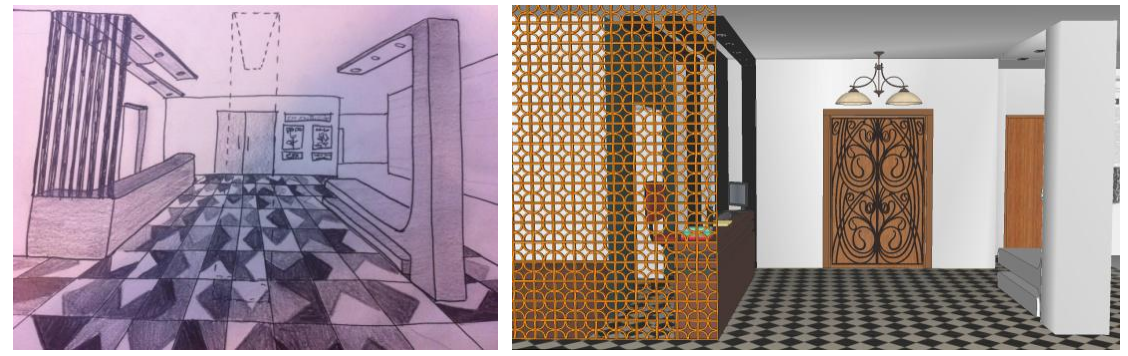

Figura 2 - Croquis da recepção da Casa de Cultura Hilda Furacão. Fonte: acervo pessoal.

O cinema tem um caráter intimista, o que o categoriza como cineclube, devido às suas dimensões físicas e seus aspectos de funcionamento, onde os usuários participam das decisões das atividades ocorridas no espaço, visando à exibição e ao 
debate de produções audiovisuais da comunidade e de filmes que não fazem parte do circuito comercial. A inspiração está no Museu de Arte da Pampulha, o antigo Cassino, tendo no espaço os materiais de luxo utilizados na época, como mármore, madeira e chapas de aço inox. A proposta é remeter ao glamour da década de 1950.

A galeria de arte tem como tema principal a ditadura (Fig. 3). Inspirada no recorte histórico ocorrido em Belo Horizonte teria, em contra partida, um caráter expositivo, que mostraria em forma de memorial e acervo fixo aquilo que foi oculto ao longo dos anos pós-regime militar. A proposta é incitar a atmosfera vivida na época pelos moradores da cidade, utilizando-se de recortes de luz e sombra para proporcionar penumbras, assim como janelas tampadas por tapumes e ripas de madeira, remetendo ao usuário o sentimento de angústia e censura da época.
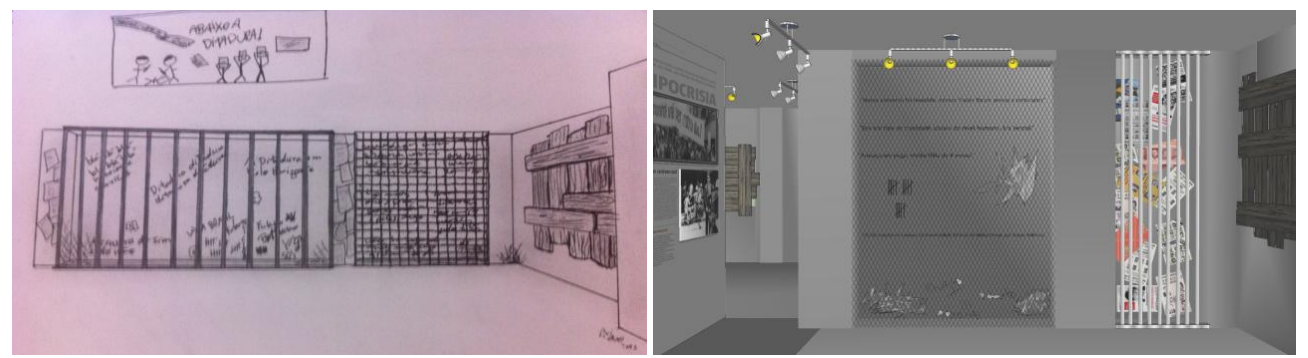

Figura 3 - Croqui e perspectiva da galeria de arte dedicada à temática da ditadura. Fonte: acervo pessoal.

Um dos acessos aos andares superiores é feito pela escada interna, e nesses corredores as paredes seriam cedidas a artistas de rua de Belo Horizonte que trabalham o tema "a verticalização da cidade" - processo de urbanização que ocorreu no período histórico em questão -, usando de inspiração as linhas dos edifícios que foram construídos entre 1950 e 1960, como o JK, o Niemeyer, o Arcângelo Maletta, o Panorama e o Conjunto IAPI.

O café-bar, que tem como objeto síntese o balcão, propõe um ambiente envolvente e sedutor. $O$ espaço também serviria como área de leitura, com um pequeno acervo de livros que contaria as histórias de Minas Gerais e de Belo Horizonte. O ambiente foi inspirado nos cafés que existiam na década de 1950 na capital e no contador de histórias "Seu Quim", do romance "Hilda Furacão", que representa as intervenções teatrais que se propõem para o espaço, onde teriam atores espalhados ao longo do café contando "causos" e estimulando os usuários a mergulharem em suas histórias. A proposta para o espaço é de fortalecer produtos da região que valorizariam a cultura e a culinária do estado e seriam fornecidos no estabelecimento.

Para que essa interação entre ambiente, história e manifestação artística contemporânea pudesse acontecer no espaço, pensou-se em um backstage em ponto estratégico, que serviria de suporte às apresentações e ao controle de iluminação, música e temperatura.

No terceiro andar, na torre da edificação, encontra-se o "Quarto 304 do Maravilhoso Hotel". Trata-se de uma ressignificação dos elementos encontrados no romance de Drummond (2008) que caracterizam a personagem principal: relógio, luminária, cama, sapato, jogo de damas, suco de groselha, perfume Muguet du Bonheur, entre outros. Seriam apresentados de uma forma irresistível e, ao mesmo tempo, subversiva, adquirindo novas funções por meio de novos materiais, permitindo 
que o quarto, além de contemplativo, fosse utilizado como um briefing room para aqueles que quisessem se encontrar para reuniões particulares de trabalho ou lazer. 0 serviço seria oferecido por meio de agendamento, no qual a casa de cultura entraria em contato com os participantes da reunião por meio de bilhetes e/ou telefonemas, remetendo aos tempos onde os encontros marcados e as cartas físicas eram habituais no dia-a-dia das pessoas.

Para o layout da área externa (Fig. 4) foram utilizadas as formas livres e sinuosas inspiradas em Oscar Niemeyer. A vegetação foi escolhida de acordo com as espécies tradicionais da cidade, auxiliando na percepção de cheiros e cores representativos da região. Jasmim, Ipê amarelo, Manacá e Hibisco são alguns dos exemplos da vegetação especificada. O piso escolhido foi a pedra portuguesa e a cerâmica, característicos da década de 1950 e 1960, que auxiliam nas formas e na dinâmica de circulação.

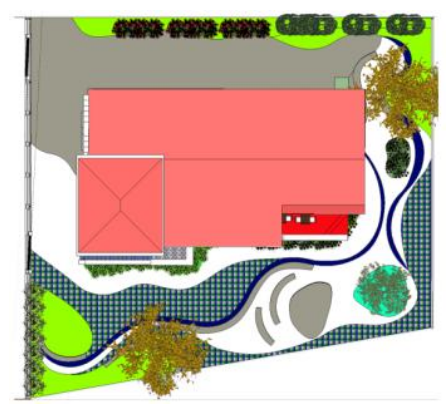

Figura 4 - Layout sem escala da área externa da Casa de Cultura Hilda Furacão. Fonte: acervo pessoal

De modo geral, a visualização do projeto de design de ambientes por meio de croquis, perspectivas e layouts permite que a equipe responsável pelo seu desenvolvimento e as pessoas responsáveis pela aprovação da solução possam repensar detalhes e planejar a execução da ideia de maneira coerente. Permite, também, que os envolvidos com o projeto possam perceber as sutilezas da solução, ou seja, avaliar os pormenores que dão sentido ao projeto.

\subsection{Resultados esperados da proposta}

A proposta desse modelo de casa de cultura entende o ambiente como meio para valorizar e preservar a identidade, a cultura, a história de um território, algo que transcenda à relação pessoas e objetos e permita que a sociedade seja imaginada e transformada a partir do seu passado.

Ao se escolher uma personagem que carrega consigo uma história, uma cultura, uma identidade, tais contextos podem ser experenciados em uma ambiência que possibilite explorar exposições, teatros, música, cinema, culinária, dança e demais expressões culturais que contem, revivam, recriem esse patrimônio. O objetivo é que a personagem e o contexto histórico e cultural que ela carrega possam ser identificados, rastreados, desmembrados e decodificados de modo a serem valorizados por meio do ambiente físico e das movimentações culturais, permitindo, assim, o fortalecimento de sua tradição e a continuidade de seu legado.

Assim, a proposta dessa configuração para casas de cultura busca promover o desenvolvimento de lugares que propiciem a reflexão, a emergência de novos valores e sociabilidades, a criação de um espaço cênico de fruição estética e sensível e a afirmação de uma identidade caracterizada pelo espírito de lugar. 


\section{CONSIDERAÇÕES FINAIS}

A partir da proposta apresentada podem-se apontar algumas considerações. Destacam-se as contribuições da atuação do designer de ambientes em uma casa de cultura, uma vez que o profissional está apto a articular as informações e a conciliar os aspectos técnico-práticos contemporâneos com os aspectos simbólicos e estéticos da época abordada, de modo a adaptá-los ao ambiente construído e a proporcionar para o usuário a imersão histórica proposta.

Para implementar propostas nesse âmbito, foram sugeridas quatro ações, apresentadas no Quadro 1.

Quadro 1 - Etapas do projeto de design de ambientes para casa de cultura.

\begin{tabular}{|l|l|}
\hline ETAPAS DO PROJETO & AÇÕES \\
\hline \multirow{2}{*}{ Pesquisa } & 1. Escolher o personagem \\
\cline { 2 - 2 } & 2. Pesquisar sobre o personagem e o seu contexto histórico-cultural \\
\hline \multirow{2}{*}{ Criação } & 3. Investigar estratégias de materialização do conteúdo \\
\cline { 2 - 2 } & 4. Consolidar ideias por meio do projeto de design para ambientes \\
\hline
\end{tabular}

Fonte: elaborado pelas autoras com base em pesquisa realizada.

Com essa reflexão espera-se contribuir para o desenvolvimento de abordagens que considerem a riqueza histórico-cultural vivida (através de personagens do passado) e a "experiência do usuário" (no contexto contemporâneo) como elementos centrais do projeto de design. Projetar um ambiente que privilegie essas dimensões pode despertar o interesse de diferentes públicos para visitação e estimular contínuas releituras do espaço, trazendo dinamicidade ao conteúdo histórico e cultural.

\section{REFERÊNCIAS}

CALEGARI, Lizandro Carlos. Do social ao estético: notas sobre "Hilda Furacão", de Roberto Drummond. Letras, v.19, n.1, Santa Maria, jan./jun. 2009. Pp. 101-115

CARVALHO, Ricardo Artur Pereira de. Livro de Guarani feito por Juruá: reflexões acerca do design do livro e da leitura a partir da escolarização dos agentes de saúde Guarani. Rio de Janeiro: Pontifícia Universidade Católica do Rio de Janeiro, 2007.

DRUMMOND, Roberto. Hilda Furacão. 18a Ed. São Paulo: Geração Editorial, 2008.

KRUCKEN, Lia. Design e território: valorização de identidades e produtos locais. São Paulo: Nobel, 2009.

MAURI, Francesco. Progettare progettando strategia: il design del sistema prodotto. Milano: Dunod, 1996.

NIEMEYER, Lucy. Identidade e significações: design atitudinal. Caderno de Estudos Avançados: identidade. Universidade do Estado de Minas Gerais. Barbacena: EdUEMG, 2010. Pp. 77-88.

ONO, Maristela Misuko. Design, cultura e identidade, no contexto da globalização. Revista Design em Foco, v. 1, n.1. Salvador, jul./dez.2004. Pp. 53-66.

PACHECO, Laura. De tudo se faz arte. Revista Sagarana, n.29, Belo Horizonte, 2007.

UNESCO. Convention for the Safeguarding of the Intangible Cultural Heritage. Paris, 17 de Out. de 2003. Tradução feita pelo Ministério das Relações Exteriores, Brasília, 2006. 